\title{
Bronchopulmonary Dysplasia: a Multidisciplinary Approach to Management
}

\author{
Jillian Connors ${ }^{1} \cdot$ Kathleen Gibbs $^{2}$ \\ Published online: 8 May 2019 \\ (C) Springer Science+Business Media, LLC, part of Springer Nature 2019
}

\begin{abstract}
Purpose of Review We aim to present the challenges in defining bronchopulmonary dysplasia (BPD) and summarize optimized management of established BPD in a multidisciplinary fashion.

Recent Findings In the last few years, several meta-analyses assessing the treatment of BPD have been updated to assist in guiding clinical management. In addition, a new severity grading system was proposed at the National Institute of Child Health and Human Development (NICHD) BPD workshop with more objective criteria including commonly used modes of noninvasive respiratory support.

Summary Although survival of infants born prematurely has improved over the last several decades, the incidence of BPD has remained unchanged. Defining BPD and stratifying its severity continue to be challenging for clinicians. Successful BPD management requires a multidisciplinary approach to optimize ventilator strategies, provide adequate nutrition, utilize pharmacotherapeutics in an evidence-based fashion, and screen for comorbidities.
\end{abstract}

Keywords Bronchopulmonary dysplasia $\cdot$ Chronic lung disease $\cdot$ Prematurity $\cdot$ Neonate

\section{Introduction}

Bronchopulmonary dysplasia (BPD), also known as chronic lung disease of prematurity, is one of the most prevalent morbidities affecting preterm infants $[1,2 \bullet, 3 \bullet \bullet, 4,5]$. Its multifactorial pathogenesis has yet to be fully elucidated, but immaturity, genetic factors, prolonged mechanical ventilation, oxygen toxicity, inflammation, arrest of alveolar development, and other factors likely contribute.

Broadly, BPD is characterized by the need for prolonged respiratory support or oxygen therapy in a preterm infant with or without chronic lung changes on chest radiograph (Fig. 1). More refined definitions with distinct clinical criteria have

This article is part of the Topical Collection on Neonatology

Jillian Connors

jconnors@montefiore.org

1 Division of Neonatology, Department of Pediatrics, The Children's Hospital at Montefiore, Albert Einstein College of Medicine, 1601 Tenbroeck Ave, 2nd Floor, Bronx, NY 10461, USA

2 Division of Neonatology, Department of Pediatrics, Children's Hospital of Philadelphia, Perelman School of Medicine at the University of Pennsylvania, Philadelphia, PA, USA evolved over time $[2 \cdot, 3 \bullet \bullet]$. Historically, BPD was diagnosed in preterm infants less than 32 weeks gestation who required supplemental oxygen for 28 days or more after birth or at 36 weeks postmenstrual age (PMA) [6]. As the provision of intensive care to extremely premature infants evolved, more granular definitions that accounted for level of immaturity and degree of disease severity were needed.

As a result, the National Institute of Child Health and Human Development (NICHD) and the National Heart, Lung, and Blood Institute (NHLBI) proposed criteria in 2000 to further stratify the severity of BPD [7]. They defined BPD as receipt of supplemental oxygen or respiratory support for more than 28 days regardless of gestational age. Severity was then assessed at 36 weeks PMA in infants less than 32 weeks gestation or prior to 56 days of age in infants 32 weeks gestation or greater. Infants off respiratory support and supplemental oxygen at time of assessment were classified as mild, those on less than $30 \% \mathrm{FiO} 2$ were classified as moderate, and those on greater than $30 \% \mathrm{FiO} 2$ or requiring positive pressure ventilation, including nasal CPAP (nCPAP), were classified as severe (Table 1). This definition presents challenges to clinicians managing extremely preterm infants in the first few weeks of life. First, the point at which severity is assessed is some time in the future, so determination of 

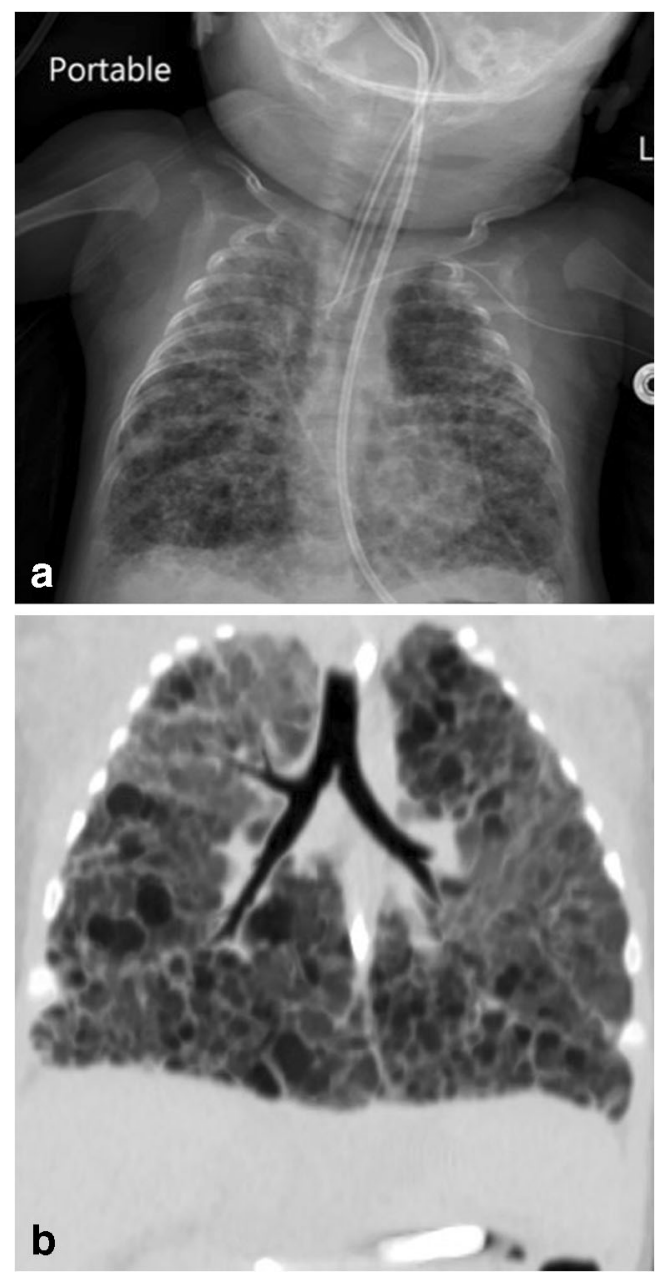

Fig. 1 Chest radiograph (a) and chest computed tomography (b) of a patient with severe BPD. a Findings include areas of cystic dilatation and atelectasis, hyperinflation, and air trapping. b These findings were confirmed on chest computed tomography. Images courtesy of Dr. Kathleen Gibbs and The Children's Hospital of Philadelphia

severity cannot be used to guide counseling or anticipate management. Second, other commonly used modes of noninvasive respiratory support, i.e., nasal intermittent positive pressure ventilation (NIPPV), high-flow nasal cannula (HFNC) with $21 \% \mathrm{FiO}$, and very low-flow nasal cannula with $100 \% \mathrm{FiO} 2$ are not addressed by the NICHD/NHLBI 2000 definition $[3 \cdot \bullet]$. As a result, the severity of BPD in a subset of infants requiring these modes of support at 36 weeks PMA cannot be determined. In addition, infants in the severe category span a variety of phenotypes. Specifically, infants who remain on nasal support at 36 weeks PMA fall into the same category as those who are intubated, require tracheostomy, or are otherwise ventilator dependent [2•]. One can imagine that the long-term outcomes for these patients might be very different. To address this, a further stratification of infants with severe BPD has been proposed, with infants requiring nCPAP, HFNC, or more than $30 \% \mathrm{FiO} 2$ considered to have Type 1 severe BPD, and with infants requiring mechanical ventilation considered to have Type 2 (Table 1). In another severe BPD cohort, patients were grouped based on whether they required supplemental oxygen, assisted ventilation, or both at 36 weeks PMA [8]. However, a comparison between subgroups showed no difference in hospital readmission rates through 2 years of followup, which was used as a surrogate measure for long-term pulmonary outcome. In 2016, the NICHD's BPD workshop proposed a new grading system for BPD from I to IIIA that included commonly used modes of non-invasive ventilation in addition to those infants who died of parenchymal lung disease and respiratory failure prior to 36 weeks PMA (Table 1) [3••]. It has yet to be demonstrated if these refined criteria more accurately predict long-term pulmonary outcomes compared with previous iterations.

Given the lack of a unifying definition that truly reflects severity of lung disease, the diagnosis of BPD may vary due to misclassified and unclassifiable cases [1]. Until that unifying definition has been determined, practitioners continue to base the diagnosis of BPD on clinical surrogates of lung disease severity, namely, level of respiratory support and oxygen requirement.

Irrespective of the definition utilized, the overall incidence of BPD has changed little over time. While the literature reports a wide range in very low-birth weight (VLBW) infants (less than $1500 \mathrm{~g}$ at birth) from 15 to $65 \%$, it is clear that rates of BPD increase as gestational age decreases $[9,10,11 \bullet]$. Antenatal and early neonatal interventions geared towards the prevention of BPD are critical in improving outcomes, but are beyond the scope of this review and will not be discussed.

\section{Management of Bronchopulmonary Dysplasia}

Once diagnosed, overall BPD management is directed at mitigating ongoing lung injury; utilizing ventilation strategies to address the underlying pathophysiology, provision of adequate nutrition to promote and pharmacologic therapies; and screening for comorbidities, particularly pulmonary hypertension and pulmonary vein stenosis. Key to the management of these patients is a multidisciplinary team approach involving neonatologists, pediatric intensive care physicians, pulmonologists, cardiologists, nutritionists, nurses, respiratory therapists, and others $[2 \cdot, 3 \cdot \bullet, 12,13]$.

\section{Ventilator Strategies}

BPD is characterized by heterogeneous hyperinflation and atelectasis increased airway resistance and air trapping, all resulting in impaired oxygenation and ventilation. For the majority of infants with BPD, clinicians are able to achieve the 
Table 1 BPD Severity vs grade: comparison of NICHD's 2000 definition with Abman's modification to NICHD's 2016 proposed definition [2•, 3••, 7]. Additional modes of respiratory support are included in the 2016 stratification to decrease number of misclassified or unclassifiable cases

\begin{tabular}{|c|c|c|c|c|c|c|c|}
\hline \multirow[t]{2}{*}{ BPD severity } & \multirow[t]{2}{*}{ Criteria at 36 weeks PMA } & \multirow{2}{*}{$\begin{array}{l}\text { BPD grade } \\
\text { Support at } \\
36 \text { weeks } \\
\text { PMA }\end{array}$} & \multicolumn{5}{|l|}{$\mathrm{FiO} 2$} \\
\hline & & & $\begin{array}{l}\text { Mechanical } \\
\text { ventilation }\end{array}$ & $\begin{array}{l}\text { nCPAP, NIPPV, } \\
\text { HFNC } \geq 3 \text { LPM }\end{array}$ & $\begin{array}{l}\text { HFNC } 1 \text { to }<3 \\
\text { LPM }\end{array}$ & $\begin{array}{l}\text { Hood } \\
\text { oxygen }\end{array}$ & $\begin{array}{l}\mathrm{NC}<1 \\
\mathrm{LMP}\end{array}$ \\
\hline Mild & Room air & I & & $21 \%$ & $22-29 \%$ & $22-29 \%$ & $22-70 \%$ \\
\hline Moderate & Supplemental oxygen $<30 \%$ & II & $21 \%$ & $22-29 \%$ & $>30 \%$ & $>30 \%$ & $>70 \%$ \\
\hline Severe Type 1 & $\begin{array}{l}\text { Supplemental oxygen } \geq 30 \% \text { or } \\
\text { positive-pressure ventilation }\end{array}$ & III & $>21 \%$ & $>30 \%$ & & & \\
\hline Type 2 & Mechanical ventilation & IIIA & \multicolumn{5}{|c|}{ Died prior to $36-\mathrm{w}$ PMA } \\
\hline
\end{tabular}

goal of optimal oxygenation and ventilation utilizing noninvasive respiratory support and the minimum amount of supplemental oxygen needed to maintain saturations within an acceptable range.

Investigation into what represents the optimal oxygen saturation target for preterm infants remains ongoing. In a recent meta-analysis of data from the SUPPORT, Canadian Oxygen Trial, and BOOST and BOOST II trials (NeOProM), infants in the lower oxygen saturation group (85-89\%) had increased risk of death and necrotizing enterocolitis but decreased risk of retinopathy of prematurity and BPD (defined as need for supplemental oxygen at 36 weeks PMA) compared with neonates in the higher saturation group (91-95\%) [14••]. There was no difference, however, in the composite outcome of death or major disability at 18-24-month corrected age.

Non-invasive respiratory support can be administered in several ways: nCPAP, NIPPV, whether synchronized or not, HFNC or very low-flow nasal cannula $[1,3 \bullet \bullet$. Evidence currently does not support the use of one mode over another in BPD management, and individual unit preference and protocol often dictate care $[4,11 \bullet, 15]$.

There is a subset of infants with severe BPD for whom noninvasive support is not possible due to the degree of lung disease or inability to wean. The philosophy of managing these infants changes; the goal is no longer to wean to the least invasive respiratory support possible, but to optimize invasive ventilation to promote growth and repair [2•]. Ventilator settings must be based upon each individual patient's underlying pathophysiology and disease phenotype. These infants may require high levels of positive end-expiratory pressure (PEEP) to overcome increased airway resistance, combat tracheobronchomalacia (TBM), and recruit lung segments prone to collapse. In addition, unlike the approach used with extremely preterm infants early in life, infants with heterogeneous lung disease may benefit from larger tidal volumes (8$12 \mathrm{ml} / \mathrm{kg}$ ), longer inspiratory times, and lower respiratory rates to optimally recruit the lung and simultaneously prevent air trapping and over-expansion $[2 \bullet, 10]$. Ventilator settings can be titrated clinically based on work of breathing, presence of tachypnea, patient-ventilator synchrony, and analysis of flowvolume loops as well as degree of expansion on chest radiographs. Blood gases are useful but are needed less frequently than were obtained earlier in life. Transcutaneous carbon dioxide monitoring may also be useful.

TBM is frequently diagnosed in infants with BPD and is present in 10 to $46 \%$ of all cases [16]. It results from immaturity of the large and small airways, weakened cartilaginous tracheal rings, and limited smooth muscle tone. It is likely exacerbated by exposure to positive-pressure ventilation resulting in tracheal enlargement and worsening dynamic airway collapse [10]. Neonates with BPD and TBM require longer hospitalizations and longer duration of mechanical ventilation, have higher incidences of gastroesophageal reflux (GER) pneumonia and need for tracheostomy compared with patients with similar severity of BPD and no TBM [16]. It is not unusual for these patients to require high levels of PEEP to stent open the large airways, particularly during expiration when dynamic airway collapse occurs, in order to ameliorate air trapping.

The complications of long-term endotracheal intubation and associated planned extubation failu res, unplanned extubations, and elective endotracheal tube up-sizing are well-known, including mucosal injury, granulomas, subglottic stenosis, and even tracheal or esophageal perforation [10]. In order to mitigate these risks and prevent complications in neonates with severe BPD, tracheostomy may ultimately be considered. There are no specific criteria to indicate optimal timing of tracheostomy; some support earlier tracheostomy to promote growth and development, while others propose delaying to avoid unnecessary tracheostomies in patients who later might be successfully weaned to non-invasive support. The decision to move forward requires ongoing multidisciplinary discussions with the care team and patients' families and an individualized approach to each patient. As a result, incidence and timing of tracheostomy vary from unit to unit based on local practices [4]. In a large multicenter retrospective cohort, $3.5 \%$ of infants born less than 30 weeks gestation underwent tracheostomy, but the incidence 
varied from 1 to $10 \%$ across different institutions [17]. In this group, neonates who underwent tracheostomy prior to 120 days of age had improved neurodevelopmental outcomes compared with those who underwent tracheostomy later. In addition, one center noted improved longitudinal growth, less need for sedation, and more frequent physical therapy to promote age-appropriate development after tracheostomy was performed [18].

\section{Nutritional Management}

Post-natal growth failure has been associated with increased risk for neonatal morbidities, including BPD [19, 20]. Provision of adequate nutrition is critical as these infants have higher metabolic demands due to increased work of breathing episodes of inflammation or infection and exposure to medications such as corticosteroids and diuretics [2•]. They not only have higher caloric requirements for somatic growth but also may need additional protein, vitamin, and electrolyte supplementation. In a Swedish cohort of infants born less than 27 weeks gestation, the risk of BPD for infants requiring more than 10 days of mechanical ventilation decreased for every $0.5 \mathrm{~g} / \mathrm{kg} /$ day increase in protein intake from 1 to 4 weeks of age [21]. An overall assessment of growth, particularly, linear and head circumference, must be monitored closely. This should continue beyond the time at which oral feeding is initiated as some infants are unable to meet their metabolic demand with oral feeds alone. In these cases, supplemental tube feeds may be considered to prevent late growth failure.

Enteral feeding with breastmilk is associated with a reduced risk of many neonatal morbidities, including BPD [22]. The beneficial effects persist beyond NICU hospitalization. Longer duration of breastmilk feeding is associated with a reduction in post-discharge respiratory illnesses, emergency room visits, courses of corticosteroids, and episodes of cough and chest congestion [23]. Early and consistent lactation support is imperative for the initiation of production and maintenance of mothers' milk supply. Because the caloric density of breastmilk is insufficient to meet the demands of an infant with BPD, fortification above and beyond what is routine for a preterm infant without BPD may be required.

Fluid restriction is frequently employed in the management of infants with BPD. Infants with BPD are prone to pulmonary edema, presumably due to immature and inadequate pulmonary lymphatic drainage. Pulmonary edema may be exacerbated by the presence of a patent ductus arteriosus with left to right shunt or inflammation resulting in capillary leak. There is no evidence, however, to support fluid restriction. In a Cochrane meta-analysis, there was no difference in duration of respiratory support, requirement for diuretics, or growth between infants with BPD receiving a high-calorie fluid-restricted diet versus those who received a standard diet [24].
GER often complicates the course of infants with BPD. GER combined with oral-motor immaturity increases the risk of aspiration. Repeated aspiration events may trigger BPD exacerbations and pulmonary hypertensive crises or cause decompensation due to tracheitis or pneumonia [12]. In the short term, some infants may benefit from continuous duodenal feeds. Ultimately, gastrostomy tube (GT) placement with or without fundoplication may be considered. GT placement with fundoplication at time of tracheostomy has been associated with improved severity of BPD and pulmonary hypertension and increased ability to wean ventilator settings.

\section{Pharmacotherapy}

As was previously discussed, infants with BPD are prone to pulmonary edema. This in turn alters lung mechanics and impairs oxygenation and ventilation. It is reasonable, then, to consider diuretic use in these infants. This has been evaluated extensively, and although there may be short-term advantages, such as an improved ability to wean oxygen or ventilator settings, differences in long-term outcomes have not been demonstrated $[11 \bullet, 25]$. There is significant variation in diuretic use across NICUs [26]. While a majority of infants with BPD receive diuretics at some point during their hospitalization, some receive short courses and others are treated chronically. Due to the lack of strong evidence that diuretic use impacts long-term pulmonary outcomes, utilization reflects local preference and practice. Close attention must be paid to adverse drug effects, including electrolyte abnormalities, acidbase derangements, and calciuria that can increase risk for nephrolithiasis and metabolic bone disease.

Corticosteroids to combat underlying inflammation that plays a role in disease pathogenesis have been investigated for both prevention and treatment of BPD. Historically, treatment with systemic corticosteroids was common, but due to an association with worse neurodevelopmental outcomes, their use fell somewhat out of favor [11•]. Recent meta-analyses, however, have demonstrated that later corticosteroids, given after 7 days of age, reduced mortality at 28 days and decreased incidence of BPD compared to placebo [27]. The side effects of systemic corticosteroids, including hyperglycemia, hypertension, gastrointestinal bleed or perforation, poor growth, and risk of infection, must be considered. In light of this, inhaled corticosteroids have been investigated as an alternative therapy due to less systemic absorption and a more favorable side effect profile. Based on two Cochrane metaanalyses, there was no difference in the incidence of BPD in infants who received inhaled versus systemic steroids both for prevention and for treatment $\left[28^{\bullet}, 29 \bullet\right]$. When inhaled corticosteroids were initiated after 7 days of age, one study found no difference in incidence of BPD, death, or a combined outcome of BPD and death compared to placebo [30•]. In a larger meta-analysis, however, early initiation of inhaled 
corticosteroids was associated with reduced incidence of death and/or BPD at 36 weeks PMA [31•]. In another cohort, there was no difference in neurodevelopmental outcomes among infants with BPD who received inhaled corticosteroids compared to placebo, but mortality was higher in the steroid group [32]. Further investigation into the utility of steroids for both the prevention and treatment of BPD, as well as the optimal timing, dosage, and formulation is warranted.

Bronchodilators, including albuterol, levalbuterol, and ipratropium, are commonly used in infants with BPD to overcome increased airway resistance and treat bronchospasm; bronchial hyper-responsiveness can persist into childhood [33]. Bronchodilator use varies considerably across NICUs, and data are insufficient to support use for BPD prevention or treatment $[11 \cdot, 34]$.

\section{Surveillance and Management of Comorbid Conditions}

\section{Pulmonary Hypertension}

Comorbid pulmonary hypertension $(\mathrm{PH})$ is diagnosed in 10 $25 \%$ of infants with severe BPD $[2 \bullet, 35]$. It results from pulmonary vascular remodeling and arteriolar muscular hypertrophy. It has been associated with significant morbidity, notably increased duration of mechanical ventilation, need for tracheostomy, and prolonged hospitalization, and it carries a significant risk of mortality. Infants with severe BPD and $\mathrm{PH}$ are more likely to have neurodevelopmental impairment at 1824 months compared with BPD survivors without PH [36]. In one cohort of infants with BPD-associated PH, the mortality rate was as high at $28 \%$ [37]. Notably, $\mathrm{PH}$ in two-thirds of survivors had resolved at time of repeat evaluation, with onethird of survivors still receiving treatment.

The Pediatric Pulmonary Hypertension Network (PPHNet) recommends screening for $\mathrm{PH}$ via echocardiography for preterm infants with a history of persistent $\mathrm{PH}$ of the newborn, infants who continue to require ventilator support at 7-days old, infants with a persistent requirement for oxygen or respiratory support and at the time of BPD severity determination (36 week PMA) [13]. Serial echocardiograms should be performed every 1 to 2 months, or sooner if the infant's clinical status changes. Echocardiography is an imperfect tool as some cases of PH may be missed. Tricuspid regurgitant jet velocity is used as a surrogate measure of pulmonary artery pressure, but if it is not sufficient to measure on echocardiogram, more qualitative measures, such as the position of the intraventricular septum or evaluation of right ventricular function are often interpreted. Scoring systems based on several qualitative and quantitative measures have been investigated with good intra-observer agreement, but results based on echocardiogram were not compared to the gold standard in $\mathrm{PH}$ diagnosis
[9]. The gold standard for diagnosis of $\mathrm{PH}$ is cardiac catheterization, but it is often reserved for very severe cases or nonresponders. Once $\mathrm{PH}$ is diagnosed, it may be useful to trend serial brain natriuretic peptide (BNP) or NT-pro-BNP in addition to obtaining serial echocardiograms to assist in guiding management [13].

Avoidance of hypoxemia and promoting pulmonary vasodilation are the cornerstones of $\mathrm{PH}$ management $[2 \bullet, 13]$. PPHNet suggests maintaining oxygen saturations in a 92 $95 \%$ range. If, despite optimal management of underlying $\mathrm{BPD}$, pulmonary vascular resistance remains high or there is concern for right ventricular dysfunction, pharmacotherapy may be indicated. Inhaled nitric oxide is a potent pulmonary vasodilator that is often used during PH crises. Other therapeutics include phosphodiesterase-5 inhibitors (Sildenafil), endothelin receptor antagonists (Bosentan), phosphdiesterase3 inhibitors, and prostacyclin analogs.

\section{Pulmonary Vein Stenosis}

Another potential and often significant comorbidity of BPD is pulmonary vein stenosis. The etiology of acquired pulmonary vein stenosis (PVS) in BPD is unclear, but obstruction of blood flow results in pulmonary venous congestion, edema, and ultimately, increased pulmonary arterial pressure [38, 39]. Echocardiogram, computed tomography (CT) angiography,z cardiac magnetic resonance imaging and cardiac catheterization have all been utilized to diagnose PVS. In one cohort of patients with PVS, 74\% also had a diagnosis of BPD. Conversely, PVS was seen in $26 \%$ of patients with BPDassociated PH [37]. Multiple treatment modalities have been employed, including surgical resection, balloon angiography, stent placement, chemotherapy, pneumonectomy, and lung transplant but restenosis is common, and cited mortality rates for patients with PVS are as high as $31 \%$.

\section{Additional Evaluation}

Lung CT may be helpful in identifying parenchymal or interstitial disease, in addition to identifying PVS if angiography is added (Fig. 1). Flexible bronchoscopy can be safely performed at the bedside and may be used to diagnose TBM, subglottic stenosis, granulomas, or other congenital anomalies of the airway as well as lower respiratory tract infections. In addition, it can be therapeutic by allowing for aspiration of mucus plugs causing regional atelectasis and can provide additional information to direct clinical management [40]. When TBM is suspected, titration of PEEP during bronchoscopy can help to establish the optimal level to prevent dynamic airway collapse. Culture and sensitivity testing of secretions or bronchoalveolar lavage specimens can direct antibiotic therapy. Not all chronic lung disease in the neonate is 
bronchopulmonary dysplasia. Cases that are atypical, particularly severe or out of proportion with level of illness or prematurity may warrant additional ezvaluation that may include genetic testing or lung biopsy. This is another example of where a multidisciplinary team approach is helpful $[2 \bullet, 3 \bullet \bullet]$.

\section{Conclusion}

BPD is a leading cause of morbidity and mortality in preterm infants. It presents many diagnostic and management challenges. Current diagnostic schemes have little relation to long-term pulmonary or neurodevelopmental outcomes. Key to the management of these patients is a multidisciplinary team approach involving neonatologists, pediatric intensive care physicians, pulmonologists, cardiologists, pulmonary hypertension specialists, nutritionists, nurses, respiratory therapists, and others. Further investigations into commonly used treatments and novel therapeutics and how they impact longterm pulmonary function neurodevelopment are still needed.

\section{Compliance with Ethical Standards}

Conflict of Interest Jillian Connors and Kathleen Gibbs declare no conflict of interest.

Human and Animal Rights and Informed Consent This article does not contain any studies with human or animal subjects performed by any of the authors.

\section{References}

Papers of particular interest, published recently, have been

highlighted as:

- Of importance

•. Of major importance

1. Poindexter BB, Feng R, Schmidt B, Aschner JL, Ballard RA, Hamvas A, et al. Comparisons and limitations of current definitions of bronchopulmonary dysplasia for the prematurity and respiratory outcomes program. Ann Am Thorac Soc. 2015;12(12):1822-30. https://doi.org/10.1513/AnnalsATS.201504-218OC.

2. Abman SH, Collaco JM, Shepherd EG, Keszler M, CuevasGuaman M, Welty SE, et al. Interdisciplinary care of children with severe bronchopulmonary dysplasia. J Pediatr. 2017;181:12-28.e1. https://doi.org/10.1016/j.jpeds.2016.10.082. Thorough review on multidisciplinary BPD care.

3.• Higgins RD, Jobe AH, Koso-Thomas M, Bancalari E, Viscardi RM, Hartert TV, et al. Bronchopulmonary dysplasia: executive summary of a workshop. J Pediatr. 2018;197:300-8. https://doi. org/10.1016/j.jpeds.2018.01.043. Important summary on BPD definitions.

4. Wright MFA, Wallis C. Investigation and management of the longterm ventilated premature infant. Early Hum Dev. 2018;126:10-7. https://doi.org/10.1016/j.earlhumdev.2018.08.015.
5. Stoll BJ, Hansen NI, Bell EF, Walsh MC, Carlo WA, Shankaran S, et al. Trends in care practices, morbidity, and mortality of extremely preterm neonates, 1993-2012. JAMA. 2015;314(10):1039-51. https://doi.org/10.1001/jama.2015.10244.

6. Shennan AT, Dunn MS, Ohlsson A, Lennox K, Hoskins EM. Abnormal pulmonary outcomes in premature infants: prediction from oxygen requirement in the neonatal period. Pediatrics. 1988;82(4):527-32.

7. Jobe AH, Bancalari E. Bronchopulmonary dysplasia. Am J Respir Crit Care Med. 2001;163(7):1723-9. https://doi.org/10.1164/ ajrccm.163.7.2011060.

8. Akangire G, Manimtim W, Nyp MF, Noel-MacDonnell J, Kays AN, Truog WE, et al. Clinical outcomes among diagnostic subgroups of infants with severe bronchopulmonary dysplasia through 2 years of age. Am J Perinatol. 2018;35(14):1376-87. https://doi. org/10.1055/s-0038-1655761.

9. McCrary AW, Barker PCA, Torok RD, Spears TG, Li JS, Hornik $\mathrm{CP}$, et al. Agreement of an echocardiogram-based diagnosis of pulmonary hypertension in infants at risk for bronchopulmonary dysplasia among masked reviewers. J Perinatol. 2019;39(2):248-55. https://doi.org/10.1038/s41372-018-0277-6.

10. Zhang H, Zhang J, Zhao S. Airway damage of prematurity: the impact of prolonged intubation, ventilation, and chronic lung disease. Semin Fetal Neonatal Med. 2016;21(4):246-53. https://doi. org/10.1016/j.siny.2016.04.001.

11. Poets CF, Lorenz L. Prevention of bronchopulmonary dysplasia in extremely low gestational age neonates: current evidence. Arch Dis Child Fetal Neonatal Ed. 2018;103(3):F285-91. https://doi.org/10. 1136/archdischild-2017-314264. Thorough review on multidisciplinary BPD care.

12. Gien J, Kinsella J, Thrasher J, Grenolds A, Abman SH, Baker CD. Retrospective analysis of an interdisciplinary ventilator care program intervention on survival of infants with ventilator-dependent bronchopulmonary dysplasia. Am J Perinatol. 2017;34(2):155-63. https://doi.org/10.1055/s-0036-1584897.

13. Krishnan U, Feinstein JA, Adatia I, Austin ED, Mullen MP, Hopper RK, et al. Evaluation and management of pulmonary hypertension in children with bronchopulmonary dysplasia. J Pediatr. 2017;188: 24-34 e1. https://doi.org/10.1016/j.jpeds.2017.05.029.

14.• Askie LM, Darlow BA, Finer N, Schmidt B, Stenson B, TarnowMordi W, et al. Association between oxygen saturation targeting and death or disability in extremely preterm infants in the neonatal oxygenation prospective meta-analysis collaboration. JAMA. 2018;319(21):2190-201. https://doi.org/10.1001/jama.2018.5725. Important meta-analysis with data on long-term outcomes.

15. Lemyre B, Laughon M, Bose C, Davis PG. Early nasal intermittent positive pressure ventilation (NIPPV) versus early nasal continuous positive airway pressure (NCPAP) for preterm infants. Cochrane Database Syst Rev. 2016;12:CD005384. https://doi.org/10.1002/ 14651858.CD005384.pub2.

16. Hysinger EB, Friedman NL, Padula MA, Shinohara RT, Zhang H, Panitch HB, et al. Tracheobronchomalacia is associated with increased morbidity in bronchopulmonary dysplasia. Ann Am Thorac Soc. 2017;14(9):1428-35. https://doi.org/10.1513/ AnnalsATS.201702-178OC.

17. DeMauro SB, D'Agostino JA, Bann C, Bernbaum J, Gerdes M, Bell EF, et al. Developmental outcomes of very preterm infants with tracheostomies. J Pediatr. 2014;164(6):1303-10 e2. https://doi. org/10.1016/j.jpeds.2013.12.014

18. Luo J, Shepard S, Nilan K, Wood A, Monk HM, Jensen EA, et al. Improved growth and developmental activity post tracheostomy in preterm infants with severe BPD. Pediatr Pulmonol. 2018;53(9): 1237-44. https://doi.org/10.1002/ppul.24087.

19. Klevebro S, Lundgren P, Hammar U, Smith LE, Bottai M, Domellof $\mathrm{M}$, et al. Cohort study of growth patterns by gestational age in preterm infants developing morbidity. BMJ Open. 
2016;6(11):e012872. https://doi.org/10.1136/bmjopen-2016012872 .

20. Underwood MA, Wedgwood S, Lakshminrusimha S, Steinhorn RH. Somatic growth and the risks of bronchopulmonary dysplasia and pulmonary hypertension: connecting epidemiology and physiology. Can J Physiol Pharmacol. 2018;97:197-205. https://doi.org/ 10.1139/cjpp-2018-0386.

21. Klevebro S, Westin V, Stoltz Sjostrom E, Norman M, Domellof M, Edstedt Bonamy AK, et al. Early energy and protein intakes and associations with growth, BPD, and ROP in extremely preterm infants. Clin Nutr. 2018. https://doi.org/10.1016/j.clnu.2018.05. 012.

22. Huang J, Zhang L, Tang J, Shi J, Qu Y, Xiong T, et al. Human milk as a protective factor for bronchopulmonary dysplasia: a systematic review and meta-analysis. Arch Dis Child Fetal Neonatal Ed. 2018;104:F128-36. https://doi.org/10.1136/archdischild-2017314205.

23. Kim LY, McGrath-Morrow SA, Collaco JM. Impact of breast milk on respiratory outcomes in infants with bronchopulmonary dysplasia. Pediatr Pulmonol. 2019;54:313-8. https://doi.org/10.1002/ ppul.24228.

24. Barrington KJ, Fortin-Pellerin E, Pennaforte T. Fluid restriction for treatment of preterm infants with chronic lung disease. Cochrane Database Syst Rev. 2017;2:CD005389. https://doi.org/10.1002/ 14651858.CD005389.pub2.

25. Donn SM. Bronchopulmonary dysplasia: myths of pharmacologic management. Semin Fetal Neonatal Med. 2017;22(5):354-8. https://doi.org/10.1016/j.siny.2017.08.002.

26. Slaughter JL, Stenger MR, Reagan PB. Variation in the use of diuretic therapy for infants with bronchopulmonary dysplasia. Pediatrics. 2013;131(4):716-23. https://doi.org/10.1542/peds. 2012-1835.

27. Doyle LW, Cheong JL, Ehrenkranz RA, Halliday HL. Late (> 7 days) systemic postnatal corticosteroids for prevention of bronchopulmonary dysplasia in preterm infants. Cochrane Database Syst Rev. 2017;10:CD001145. https://doi.org/10.1002/ 14651858.CD001145.pub4.

28. Shah SS, Ohlsson A, Halliday HL, Shah VS. Inhaled versus systemic corticosteroids for preventing bronchopulmonary dysplasia in ventilated very low birth weight preterm neonates. Cochrane Database Syst Rev. 2017;10:CD002058. https://doi.org/10.1002/ 14651858.CD002058.pub3. Updated Cochrane review.

29. Shah SS, Ohlsson A, Halliday HL, Shah VS. Inhaled versus systemic corticosteroids for the treatment of bronchopulmonary dysplasia in ventilated very low birth weight preterm infants. Cochrane Database Syst Rev. 2017;10:CD002057. https://doi.org/10.1002/ 14651858.CD002057.pub4. Updated Cochrane review.

30. Onland W, Offringa M, van Kaam A. Late ( $>/=7$ days) inhalation corticosteroids to reduce bronchopulmonary dysplasia in preterm infants. Cochrane Database Syst Rev. 2017;8:CD002311. https://
doi.org/10.1002/14651858.CD002311.pub4. Updated Cochrane review.

31. Shah VS, Ohlsson A, Halliday HL, Dunn M. Early administration of inhaled corticosteroids for preventing chronic lung disease in very low birth weight preterm neonates. Cochrane Database Syst Rev. 2017;1:CD001969. https://doi.org/10.1002/14651858. CD001969.pub4. Updated Cochrane review.

32. Bassler D, Shinwell ES, Hallman M, Jarreau PH, Plavka R, Carnielli V, et al. Long-term effects of inhaled budesonide for bronchopulmonary dysplasia. N Engl J Med. 2018;378(2):14857. https://doi.org/10.1056/NEJMoa1708831.

33. Kotecha S, Clemm H, Halvorsen T, Kotecha SJ. Bronchial hyperresponsiveness in preterm-born subjects: a systematic review and meta-analysis. Pediatr Allergy Immunol. 2018;29(7):715-25. https://doi.org/10.1111/pai.12957.

34. Ng G, da Silva O, Ohlsson A. Bronchodilators for the prevention and treatment of chronic lung disease in preterm infants. Cochrane Database Syst Rev. 2016;12:CD003214. https://doi.org/10.1002/ 14651858.CD003214.pub3.

35. Lagatta JM, Hysinger EB, Zaniletti I, Wymore EM, Vyas-Read S, Yallapragada S, et al. The impact of pulmonary hypertension in preterm infants with severe bronchopulmonary dysplasia through 1 year. J Pediatr. 2018;203:218-24 e3. https://doi.org/10.1016/j. jpeds.2018.07.035.

36. Choi EK, Shin SH, Kim EK, Kim HS. Developmental outcomes of preterm infants with bronchopulmonary dysplasia-associated pulmonary hypertension at 18-24 months of corrected age. BMC Pediatr. 2019;19(1):26. https://doi.org/10.1186/s12887-019-14003.

37. Altit G, Bhombal S, Hopper RK, Tacy TA, Feinstein J. Death or resolution: the "natural history" of pulmonary hypertension in bronchopulmonary dysplasia. J Perinatol. 2019;39:415-25. https://doi.org/10.1038/s41372-018-0303-8.

38. Mahgoub L, Kaddoura T, Kameny AR, Lopez Ortego P, Vanderlaan RD, Kakadekar A, et al. Pulmonary vein stenosis of ex-premature infants with pulmonary hypertension and bronchopulmonary dysplasia, epidemiology, and survival from a multicenter cohort. Pediatr Pulmonol. 2017;52(8):1063-70. https:// doi.org/10.1002/ppul.23679.

39. Swier NL, Richards B, Cua CL, Lynch SK, Yin H, Nelin LD, et al. Pulmonary vein stenosis in neonates with severe bronchopulmonary dysplasia. Am J Perinatol. 2016;33(7):671-7. https://doi.org/10. 1055/s-0035-1571201.

40. Hysinger E, Friedman N, Jensen E, Zhang H, Piccione J. Bronchoscopy in neonates with severe bronchopulmonary dysplasia in the NICU. J Perinatol. 2019;39(2):263-8. https://doi.org/10. 1038/s41372-018-0280-y.

Publisher's Note Springer Nature remains neutral with regard to jurisdictional claims in published maps and institutional affiliations. 